\title{
Management of Difficult Bile Duct Stones by Large Balloon, Cholangioscopy, Enteroscopy and Endosonography
}

\author{
Yousuke Nakai ${ }^{1,2}$, Tatsuya Sato ${ }^{2}$, Ryunosuke Hakuta ${ }^{2}$, Kazunaga Ishigaki ${ }^{2}$, Kei Saito ${ }^{2}$, Tomotaka Saito ${ }^{2}$, Naminatsu Takahara ${ }^{2}$, \\ Tsuyoshi Hamada ${ }^{2}$, Suguru Mizuno ${ }^{2}$, Hirofumi Kogure ${ }^{2}$, Minoru Tada ${ }^{2}$, Hiroyuki Isayama ${ }^{3}$, and Kazuhiko Koike ${ }^{2}$ \\ Departments of ${ }^{1}$ Endoscopy and Endoscopic Surgery and ${ }^{2}$ Gastroenterology, Graduate School of Medicine, The University of Tokyo, and \\ ${ }^{3}$ Department of Gastroenterology, Graduate School of Medicine, Juntendo University, Tokyo, Japan
}

Endoscopic management of bile duct stones is now the standard of care, but challenges remain with difficult bile duct stones. There are some known factors associated with technically difficult bile duct stones, such as large size and surgically altered anatomy. Endoscopic mechanical lithotripsy is now the standard technique used to remove large bile duct stones, but the efficacy of endoscopic papillary large balloon dilatation (EPLBD) and cholangioscopy with intraductal lithotripsy has been increasingly reported. In patients with surgically altered anatomy, biliary access before stone removal can be technically difficult. Endotherapy using two new endoscopes is now utilized in clinical practice: enteroscopyassisted endoscopic retrograde cholangiopancreatography and endoscopic ultrasound-guided antegrade treatment. These new approaches can be combined with EPLBD and/ or cholangioscopy to remove large bile duct stones from patients with surgically altered anatomy. Since various endoscopic procedures are now available, endoscopists should learn the indications, advantages and disadvantages of each technique for better management of bile duct stones. (Gut Liver 2020;14:297-305)

Key Words: Cholangioscope; Choleodcholithiasis; Cholangiopancreatography, endoscopic retrograde; Endosonography; Lithotripsy

\section{INTRODUCTION}

Bile duct stones (BDS) are one of the most common biliary tract diseases with a prevalence of $10 \%$ to $20 \%$ of symptomatic gallbladder stones. ${ }^{1}$ There are two types of BDS; primary de novo stones and secondary stones. Primary BDS arise within the intrahepatic and/or extrahepatic ducts and are common in Asian population. Meanwhile, secondary BDS migrate into the bile duct from the gallbladder, which are common in Western population. Although a natural history of asymptomatic BDS is not fully elucidated, ${ }^{2}$ BDS can cause various symptoms such as abdominal pain, obstructive jaundice, cholangitis and pancreatitis, which can be potentially fatal. Endoscopic retrograde cholangiopancreatography (ERCP) with endoscopic sphincterotomy $(\mathrm{ES})^{3}$ is an established treatment for BDS with technical success rates of $85 \%$ to $90 \%$. In the remaining $10 \%$ to $15 \%$, additional techniques or devices are often necessary to manage those "difficult" BDS. ${ }^{4}$

\section{WHAT ARE DIFFICULT BDS?}

The reasons for difficulty include stone characteristics, the anatomy, patients' conditions and endoscopists' skills. There are some steps for endoscopic stone removal: access to the ampulla and biliary system, ampullary interventions and stone extraction. Endoscopists can encounter technical hurdles throughout those steps as shown in Table 1. The definition of difficult BDS can vary among endoscopists because difficult BDS for trainees is not always difficult for experts. However, large BDS ${ }^{5}$ and surgically altered anatomy ${ }^{6}$ are two major reasons for technical difficulty.

In cases with large BDS, there are two recent approaches for stone extraction: endoscopic papillary large balloon dilatation $(\mathrm{EPLBD})^{7}$ and intraductal lithotripsy under the guidance of peroral cholangioscopy (POCS). ${ }^{8,9}$ On the other hand, biliary access is the major issue in cases with surgically altered anatomy. In the past, ERCP using a conventional duodenoscope or forward viewing scope was performed but the technical success rate was

\footnotetext{
Correspondence to: Yousuke Nakai

Department of Endoscopy and Endoscopic Surgery, Graduate School of Medicine, The University of Tokyo, 7-3-1 Hongo Bunkyo-ku, Tokyo 1138655, Japan

Tel: +81-3-3815-5411, Fax: +81-3-5800-9801, E-mail: ynakai-tky@umin.ac.jp

Received on May 8, 2019. Revised on July 19, 2019. Accepted on July 28, 2019. Published online October 8, 2019. pISSN 1976-2283 eISSN 2005-1212 https://doi.org/10.5009/gnl19157

(a) This is an Open Access article distributed under the terms of the Creative Commons Attribution Non-Commercial License (http://creativecommons.org/licenses/by-nc/4.0) which permits unrestricted non-commercial use, distribution, and reproduction in any medium, provided the original work is properly cited.
} 
Table 1. Factors Underlying Difficult Bile Duct Stones

\begin{tabular}{|c|c|c|}
\hline Category & Conditions & Reasons for difficulty \\
\hline \multirow[t]{2}{*}{ Patient characteristics } & Unstable condition & Risk for adverse events \\
\hline & Coagulopathy & Risk for bleeding \\
\hline \multirow[t]{3}{*}{ Anatomy } & Surgically altered anatomy & Scope insertion, biliary cannulation \\
\hline & Periampullary diverticulum & Biliary cannulation \\
\hline & Biliary stricture & Stone extraction \\
\hline \multirow[t]{2}{*}{ Stone characteristics } & Large stone & Need for lithotripsy \\
\hline & Impacted stone & Need for cholangioscopy \\
\hline Endoscopist & Less experienced & Less skills and knowledge \\
\hline
\end{tabular}
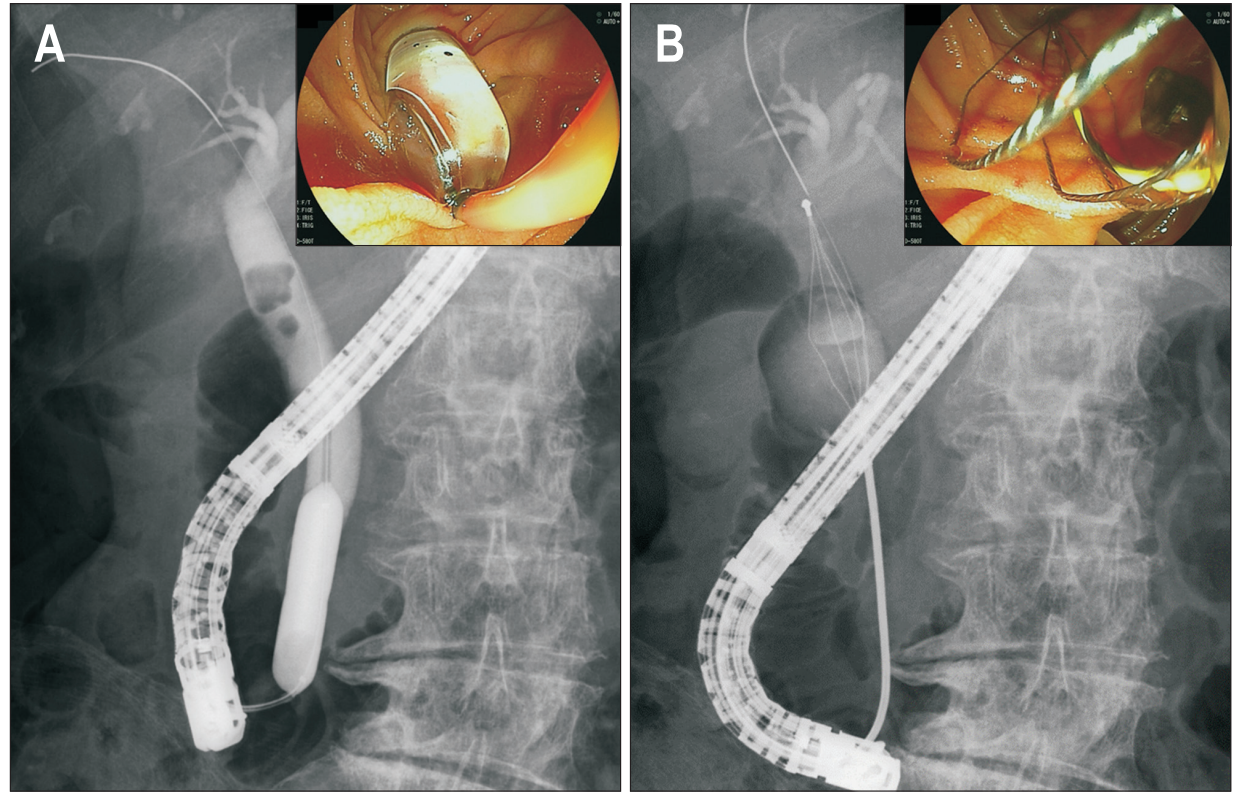

Fig. 1. Endoscopic papillary large balloon dilation. (A) The ampulla was dilated with a large balloon. (B) A bile duct stone was extracted without lithotripsy. not satisfactory. ${ }^{6}$ In failed cases, salvage by percutaneous or surgical approach has been performed. Recently, two endoscopic approaches are increasingly utilized for management of BDS in surgically altered anatomy patients: enteroscopy-assisted ERCP ${ }^{10}$ and endoscopic ultrasound (EUS)-guided approach. ${ }^{11,12}$ Herein, these new modalities for difficult BDS are reviewed.

\section{ENDOSCOPIC PAPILLARY LARGE BALLOON DILATATION}

ES is the standard ampullary intervention for endoscopic management of BDS. ${ }^{3}$ While endoscopic papillary balloon dilation (EPBD) is an alternative to $\mathrm{ES},{ }^{13,14}$ it was reportedly associated with an increased risk of post-ERCP pancreatitis (PEP) ${ }^{15}$ The longterm outcomes such as recurrent BDS are reportedly superior to those of $\mathrm{ES}^{16}$ but EPBD is not widely used due to the increased risk of PEP. More recently, EPLBD, which was first described by Ersoz et al. ${ }^{17}$ in 2003 , is increasingly utilized for difficult BDS. In EPLBD, the ampulla was dilated using a balloon $>10 \mathrm{~mm}$, which allows extraction of large BDS even without lithotripsy (Fig. 1). In a meta-analysis of EPLBD and $\mathrm{ES},{ }^{18}$ technical success rate was similar (98\% in EPLBD and 95\% in ES) but the use of mechanical lithotripsy (ML) was less often necessary after EPLBD. While ML was performed in 32\% in ES, the rate of ML use was only 15\% in EPLBD. Furthermore, EPLBD reduced adverse events (11\% in EPLBD and 18\% in ES), suggesting better safety and effectiveness of EPLBD for large BDS.

Whether EPLBD should be preceded by ES or not is a matter of debate. EPLBD was originally preceded by ES but in a multicenter retrospective analysis, ${ }^{19}$ a large size ES was associated with bleeding with an odds ratio of 6.22. And a recent randomized controlled trial $(\mathrm{RCT})^{20}$ showed similar efficacy and safety between EPLBD alone and EPLBD with ES. The adverse event rates were $6 \%$ and $4 \%(p=0.75)$ and PEP rates were $1 \%$ and $3 \%$ $(p=0.62)$ in EPLBD alone and EPLBD with ES. Complete stone removal was achieved in 92\% and 88\%, and the use of ML was necessary in 6.5\% in EPLBD alone and 9.1\% in EPLBD with ES $(\mathrm{p}=0.39)$.

Since the number of patients who were on antithrombotic agents is increasing rapidly in clinical practice, EPLBD without ES may be recommended in those patients on antithrombotic 
agents to avoid bleeding complications. ${ }^{21}$

While safety and efficacy of EPLBD have been proven, the diameter of balloon was limited to the size of distal bile duct. In addition, EPLBD is contraindicated in cases with distal biliary stricture due to the risk of perforation. ${ }^{19}$ Thus, if the size of BDS is larger than that of distal bile duct, ${ }^{22}$ lithotripsy is necessary for stone extraction even after EPLBD.

\section{CHOLANGIOSCOPY-ASSISTED LITHOTRIPSY}

ML is a standard method for lithotripsy in cases with large BDS. The technical success rate of ML is about $90 \%{ }^{23,24}$ but ML can be technically challenging depending on the size and location of BDS. The technical success rate of ML was 67.6\% in cases with stones $>2.5 \mathrm{~cm} .^{23}$ An impacted stone was a risk factor for failed $\mathrm{ML}^{25}$ and a confluence stone is also technically challenging.

Extracorporeal shock wave lithotripsy (ESWL) ${ }^{26}$ is a treatment option but can be time consuming and needs a nasobiliary drainage tube placement, which causes discomfort to patients. Since the introduction of single-operator cholangioscopy, cholangioscope-assisted intraductal lithotripsy is increasingly utilized. POCS allows lithotripsy under direct visualization using electrohydraulic lithotripsy (EHL) and laser lithotripsy (Fig. 2).

There are three types of cholangioscopy available now: dualoperator "mother-baby" cholangioscopy, single-operator "mother-baby” cholangioscopy and direct cholangioscopy (Table 2).

In a RCT of laser lithotripsy under endoscopic or percutane- ous cholangioscope and ESWL, ${ }^{27}$ the rate of stone clearance was significantly higher in laser lithotripsy (97\%) than in ESWL (73\%). Comparison of EHL and laser lithotripsy is summarized in Table 3. A recent systematic review ${ }^{28}$ also demonstrated that laser lithotripsy had a higher complete ductal clearance rate (95.1\%) than EHL (88.4\%) and ESWL (84.5\%, p<0.001). Meanwhile, the adverse event rate was significantly higher in EHL

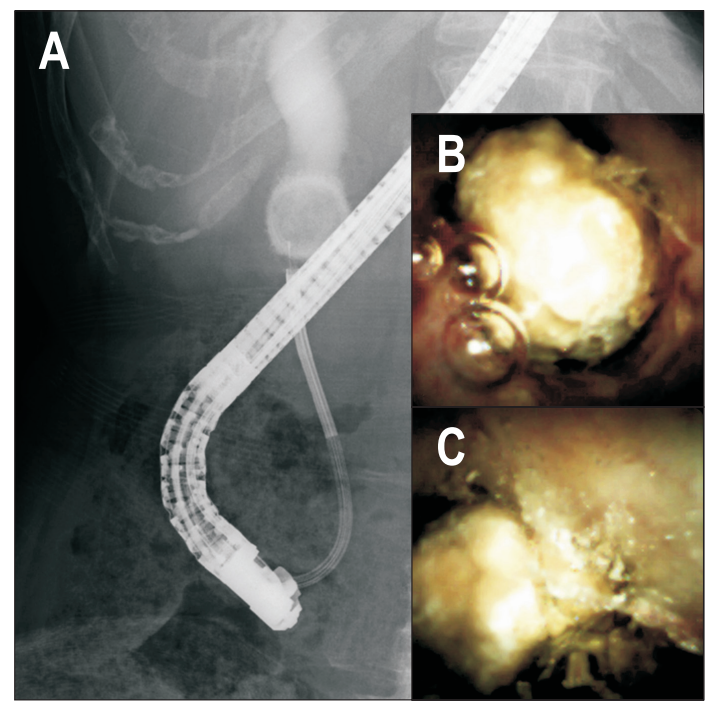

Fig. 2. Per-oral cholangioscopy-assisted electrohydraulic lithotripsy (EHL). (A) A digital cholangioscope was inserted into the bile duct. (B) A large bile duct stone was visualized. (C) EHL was performed under direct visualization.

Table 2. Comparison of Three Cholangioscopy Systems

\begin{tabular}{lccc}
\hline \multicolumn{1}{c}{ Variable } & $\begin{array}{c}\text { Dual-operator } \\
\text { "mother-baby" cholangioscopy }\end{array}$ & $\begin{array}{c}\text { Single-operator } \\
\text { "mother-baby" cholangioscopy }\end{array}$ & Direct cholangioscopy \\
\hline Endoscopists & Two & Single & Single \\
Need for additional processor & Yes & Yes & No \\
Steering & 2 Directions & 4 Directions & $2-4$ Directions \\
Scope diameter, mm & $3.3-3.5$ & 3.6 & $5-6$ \\
Working channel diameter, mm & 1.2 & 1.2 & 2 \\
Dedicated irrigation channel & No & Yes & No \\
Image quality & Very good & Good & Very good \\
Image enhanced endoscopy & Yes & No & Yes \\
Technical ease for biliary access & Yes & Yes & No \\
Maneuverability & Good & Very good & Needs expertise \\
Cost & High & High & Low \\
\hline
\end{tabular}

Table 3. Comparison of EHL and Laser Lithotripsy for the Removal of Difficult Bile Duct Stones

\begin{tabular}{cccll}
\hline & Complete duct clearance rate $^{28}$ & Complication rate ${ }^{28}$ & \multicolumn{1}{c}{ Advantages } & \multicolumn{1}{c}{ Disadvantages } \\
\hline EHL & 88.4 & 13.8 & A small generator, inexpensive & Risk of bleeding and perforation \\
Laser & 95.1 & 9.6 & Less traumatic & A large machine, expensive \\
\hline
\end{tabular}

EHL, electrohydraulic lithotripsy. 
(13.8\%) than in ESWL (8.4\%) or laser lithotripsy (9.6\%, p=0.04). Thus, laser lithotripsy provides better clinical outcomes in large BDS but it may depend on the local expertise and availability of each technique. In a recent multicenter, international, retrospective analysis of digital cholangioscopy for difficult BDS, technical success and adverse event rates were comparable: 96.7\% versus 99\% ( $p=0.31)$ and 3.3\% versus 5.0\% ( $p=0.54)$ in $E H L$ and laser lithotripsy groups. However, the procedure time was significantly longer in EHL group (73.9 minutes vs 49.9 minutes, $\mathrm{p}<0.001)^{9}$

There are two recent RCTs comparing POCS-assisted lithotripsy and the standard technique. ${ }^{29,30}$ Buxbaum et al..$^{29}$ compared POCS-assisted lithotripsy and the conventional technique including $\mathrm{ML}$ and EPLBD for BDS $>1 \mathrm{~cm}$. Complete stone removal rates were 93\% in P0CS-assisted lithotripsy and 67\% in the conventional treatment without significant differences in the rates of adverse events (9.5\% and 11.1\%). However, the procedure time was significantly longer in POCS-assisted lithotripsy group (120.7 and 81.2 minutes). Another RCT by Angsuwatcharakon et al. ${ }^{30}$ compared POCS-guided laser lithotripsy and ML after failed EPLBD. Complete stone removal rates in a single session were 100\% and 63\% with comparable adverse events (6\% and 13\%) in the POCS group and the ML group. In this study, the procedure time was not significantly different (66 and 83 minutes) and the fluoroscopy time was significantly shorter (11 and 21 minutes) in the POCS group. Cost of POCS should also be discussed in the era of medical cost effectiveness, given the high price of a single-use digital cholangioscope. In the cost-effective analysis by Deprez et al., ${ }^{31}$ however, the use of cholangioscope for difficult BDS would decrease the number of procedures by $28 \%$ and the cost by $11 \%$, respectively. In summary, POCS-assisted lithotripsy can be a standard of care in terms of safety, efficacy and cost effectiveness for large BDS.

\section{ENTEROSCOPY-ASSISTED ERCP}

Endoscopic management of BDS in patients with surgically altered anatomy is still technically demanding. ${ }^{6}$ In cases with Billroth II reconstruction or Roux-en-Y reconstruction, scope insertion can be difficult or impossible in some cases, and even after scope insertion both biliary cannulation and stone extraction pose technical hurdles to endoscopists. Recent development of enteroscopes dedicated for therapeutic ERCP allows easy scope insertion and the use of various ERCP devices (Fig. 3). ${ }^{32-34}$

In cases with surgically altered anatomy, the size of BDS is often too large for stone extraction without lithotripsy. Various techniques described above can be applied in this setting. Single-session and overall complete stone removal rates in surgically altered anatomy patients are reportedly $66.7 \%$ to $100 \%$ and $96.7 \%$ to $100 \%$, respectively, using EPLBD. ${ }^{6}$ ML can be performed using recently developed enteroscopes ${ }^{33,34}$ with short scope length and a large channel but the size of BDS is limited to $<2-3 \mathrm{~cm}$ for successful lithotripsy by ML. Furthermore, the insertion and manipulation of a stiff ML device is often technically challenging during enteroscopy-assisted ERCP.

POCS is not readily available in patients with surgically altered anatomy but some technical tips ${ }^{35-40}$ have been reported to perform POCS in this setting; direct insertion of enteroscopes into the bile duct, insertion of ultra-slim endoscope or cholangioscope into the bile duct with a help of the overtube of enteroscopes. Although POCS-guided lithotripsy is useful in patients with surgically altered anatomy, the procedure should be performed using $\mathrm{CO}_{2}$ insufflation to decrease the risk of air embolism. Intraabdominal pressure is often high with retained gas or $\mathrm{CO}_{2}$ after enteroscope insertion and additional insufflation in the bile duct may increase the risk of embolism, though its incidence is not fully elucidated.
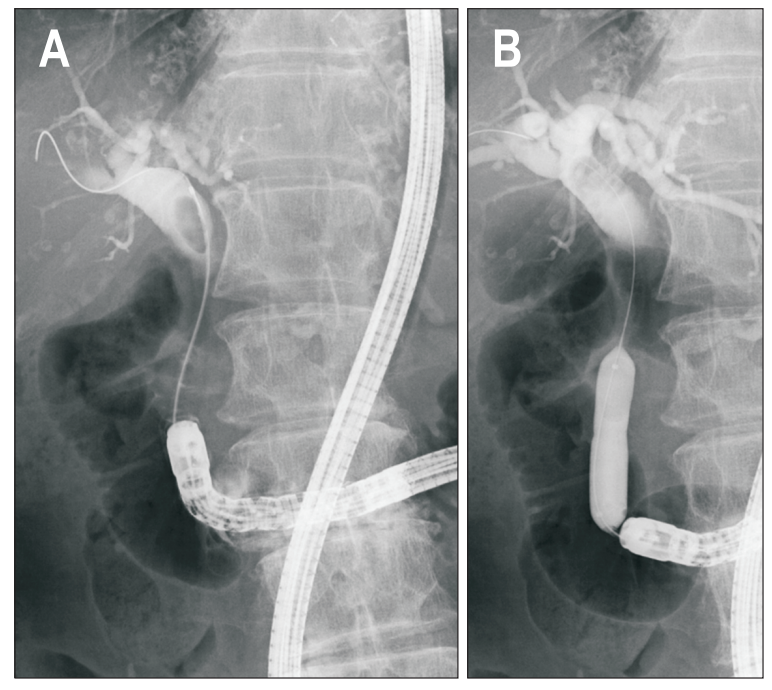

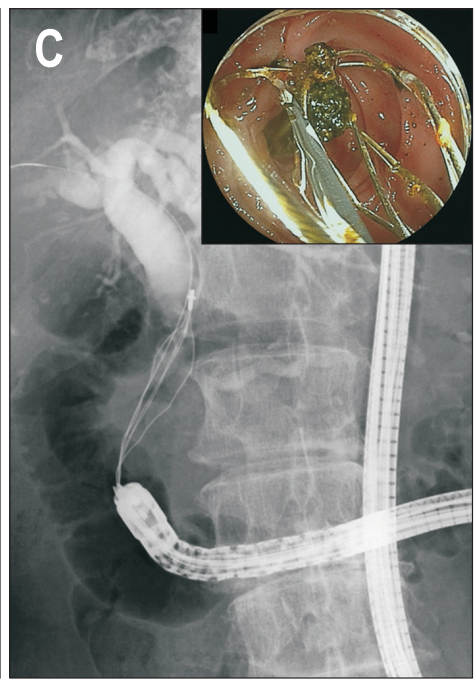

Fig. 3. Enteroscopy-assisted endoscopic retrograde cholangiopancreatography. (A) Cholangiogram revealed bile duct stones. (B) Endoscopic papillary large balloon dilation was performed. (C) Bile duct stones were extracted with a basket catheter. 


\section{EUS-GUIDED STONE MANAGEMENT}

EUS-guided biliary interventions are increasingly utilized after failed or difficult ERCP. ${ }^{11,12}$ EUS-guided rendezvous (EUS$\mathrm{RV})^{41}$ and EUS-guided antegrade (EUS-AG) treatment are two major techniques used for endoscopic management of BDS. EUS-RV is useful in cases with accessible ampulla but failed biliary cannulation ${ }^{42}$ and subsequent procedure after biliary access is similar to the conventional ERCP. On the other hand, EUSAG is a technique useful for inaccessible ampulla, especially in those with surgically altered anatomy. ${ }^{43-45}$

In EUS-AG stone treatment, biliary access is achieved from the stomach or jejunum under EUS-guidance. After guidewire passage through the ampulla into the duodenum, the ampulla is dilated using a balloon. Finally, BDS is antegradely pushed out using a stone extraction balloon (Fig. 4). In a multicenter retrospective study, ${ }^{46}$ its technical success rate was $72 \%$ with its adverse event rate of $17 \%$. The major reason for technical failure was failed puncture of the intrahepatic bile duct, which is often minimally dilated in this setting. However, guidewire passage and stone extraction through the ampulla can be a reason for technical failure, too. To overcome these technical hurdles, approach to difficult BDS such as large balloon dilation and intraductal lithotripsy, which are discussed above, can be applied to EUS-AG.

During EUS-AG stone treatment, ES is technically impossible and the ampullary intervention is limited to papillary balloon dilatation. In cases with a large distal common bile duct (CBD), large balloon dilatation can be performed to enhance stone extraction. However, the balloon size is limited to the size of distal CBD and intraductal lithotripsy is necessary in cases with BDS larger than the size of distal CBD but the use of multiple devices with a prolonged procedure time can increase the risk of bile leak. To prevent bile leak, a two-step approach allows safe use of ML and cholangioscopy in EUS-AG stone treatment. ${ }^{47}$ In this two-step approach, only EUS-hepaticogastrostomy (EUS-HGS) or EUS-hepaticojejunostomy (EUS-HJS) is created in the first session, which can be completed in a short time and the risk of bile leak is small because there is no need to pass the guidewire through the ampulla or to extract BDS after the ampullary in-
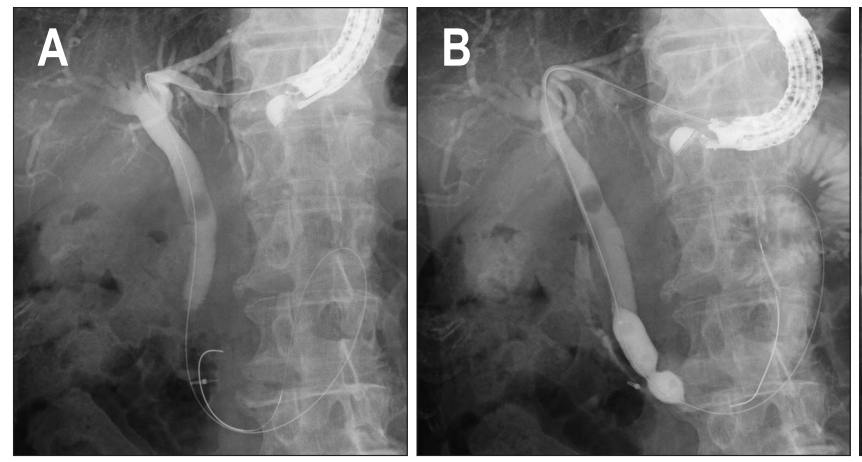

tervention. In the second session, HGS or HJS fistula is matured and stone extraction devices can be introduced through the mature fistula without a risk of bile leak. Although there have been no reports on the exact duration necessary for mature fistula creation but in general the second session can be safely performed 2 to 4 weeks after the first session. Intraductal lithotripsy can be performed using ML or POCS-guided lithotripsy, which was increasingly reported in recent papers. ${ }^{48-50}$ The mature fistula can be readily dilated using a bougie dilator or a balloon dilator before device insertion, depending on the size of devices used for lithotripsy. While ML can be introduced into the bile duct through the fistula over the guidewire easily, dilation up to $10-\mathrm{F}$ is necessary if digital cholangioscopy-assisted lithotripsy is necessary after EUS-HGS or EUS-HJS using a plastic stent. Alternatively, a large bore fully-covered metal stent can also be utilized both to prevent bile leak and to allow easy access to the biliary system. The devices used for lithotripsy during EUSguided approach are similar to ERCP approach: ML, ESWL and cholangioscopy-assisted laser lithotripsy and EHL. ${ }^{51}$

While most EUS-BD procedures were initially performed for unresectable malignant biliary obstruction, advanced EUS-guided management of benign biliary diseases including complex BDS has been increasingly reported (Table 4). Hosmer et al. ${ }^{48}$ reported a single center experience of nine cases with Roux-en-Y anatomy with the technical success rate of stone extraction was $100 \%$. Balloon dilation of the ampulla $\geq 10 \mathrm{~mm}$ was performed in $89 \%$ and cholangioscopy-assisted EHL was performed in 44\%. James et al. ${ }^{49}$ reported EUS-guided hepaticoenterostomy as a portal to allow definitive antegrade treatment of benign biliary diseases including eight cases with BDS. Stone clearance was successful in 100\% with a combined balloon dilation and cholangioscopy. Mukai et al. ${ }^{50}$ also reported EUS-guided treatment of 37 cases with benign biliary diseases. They applied twostage interventions when a complex procedure was expected such as in cases with BDS $\geq 15 \mathrm{~mm}$ or with tight biliary stricture. POCS-assisted lithotripsy was utilized in 13 BDS cases with a technical success rate of 100\%. We can select the lithotripsy technique depending on characteristics of patients and BDS but there are no comparative studies of lithotripsy in EUS-guided approach. Thus, the technique can be selected according to the
Fig. 4. Endoscopic ultrasoundguided antegrade stone treatment. (A) Biliary access was achieved under endoscopic ultrasound guidance. (B) The ampulla was dilated with a balloon. (C) Bile duct stones were extracted in an antegrade manner using a balloon catheter. 


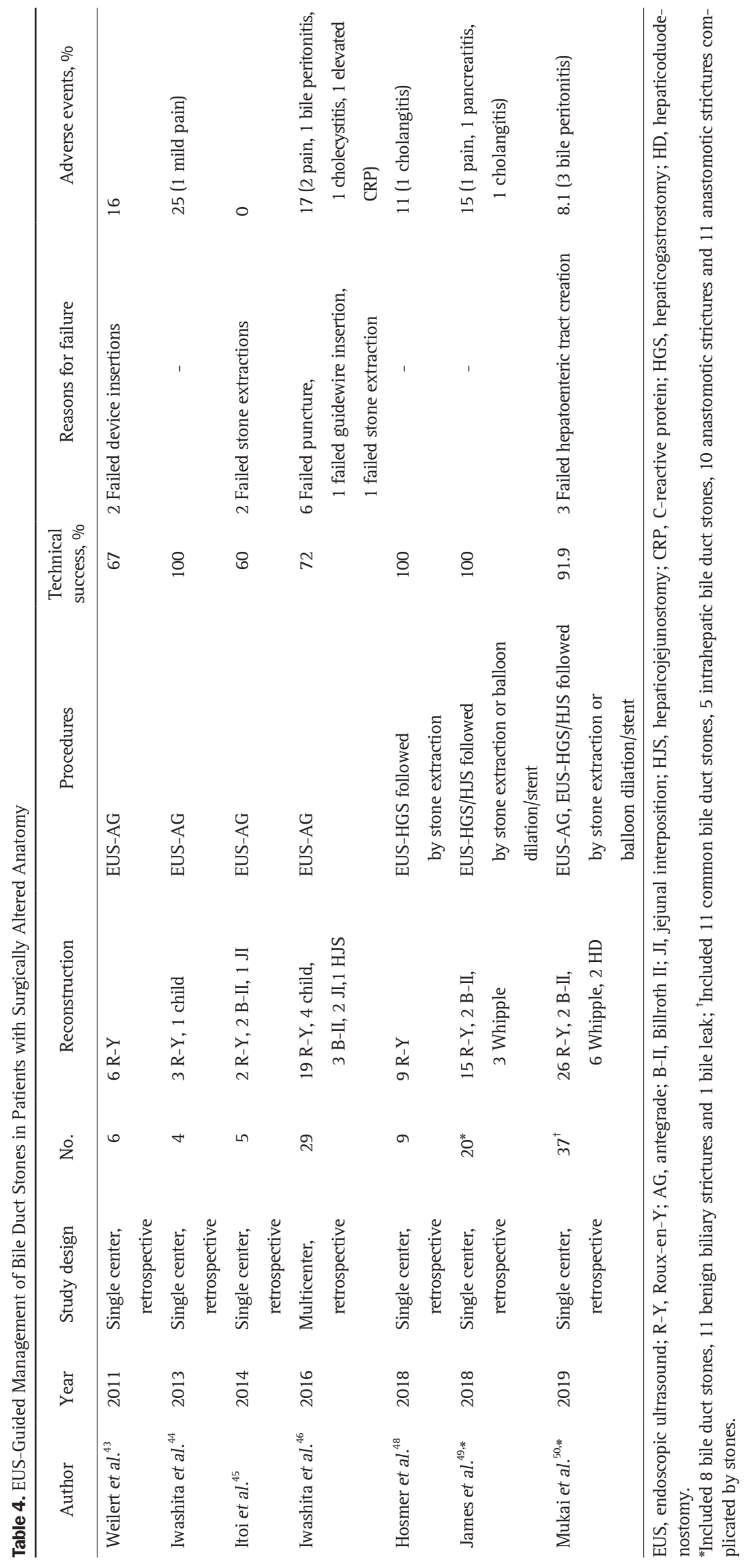


Table 5. Comparisons of Enteroscopy-Assisted and Endoscopic Ultrasound-Guided Stone Management

\begin{tabular}{|c|c|c|}
\hline & Advantages & Disadvantages \\
\hline \multirow[t]{2}{*}{ Enteroscopy-assisted procedure } & No bile leak & Difficult scope insertion \\
\hline & Physiological route & Can be time consuming \\
\hline \multirow[t]{2}{*}{ Endoscopic ultrasound-guided procedure } & Short scope insertion time & Risk of bile leak \\
\hline & Combined with a cholangioscope & No dedicated devices \\
\hline
\end{tabular}

local expertise or preferences.

There are some advantages and disadvantages for EUS- and enteroscopy-assisted stone management in cases with surgically altered anatomy (Table 5). While enterosocpy-assisted ERCP utilizes the physiological biliary access and has a low risk of bile leak, scope insertion can be technically difficult or even impossible depending on the anatomy. On the other hand, in EUS-guided approach, there is no need for deep scope insertion but the approach is limited to the left intrahepatic bile duct. Sometimes, biliary dilation is minimal and the puncture of the bile duct can be technically difficult. In addition, the risk of bile leak does exist in EUS-guided approach. Treatment algorithm for BDS should be established in cases with surgically altered anatomy. Currently, enteroscopy-assisted ERCP is often the first approach. After failed enteroscopy-assisted ERCP, EUS-guided approach can be a salvage technique if biliary access to the left intrahepatic bile duct is acceptable. When the right intrahepatic bile duct approach is necessary, percutaneous transhepatic biliary drainage should be selected. We previously proposed this algorithm in our review ${ }^{52}$ and clinical outcomes of this algorithm should be confirmed in prospective studies. Finally, both enteroscopy-assisted ERCP and EUS-AG stone treatment need expertise as well as dedicated devices, and we recommend those procedures should be performed by experts in high volume centers.

\section{SUMMARY}

Endoscopic management of BDS has been established as a standard of care but there still exist difficult BDS in clinical practice. Some emerging techniques and devices such as EPLBD, cholangioscope, enteroscopy-assisted ERCP and EUS-AG are increasingly utilized with reportedly high technical success rates and acceptable adverse event rates. Endoscopists should learn the indications, advantages and disadvantages of each technique for better management of difficult BDS. Treatment algorithm for difficult BDS according to the stone characteristics and the patient anatomy is to be further established in the future.

\section{CONFLICTS OF INTEREST}

No potential conflict of interest relevant to this article was reported.

\section{ORCID}

Yousuke Nakai

Tatsuya Sato

Ryunosuke Hakuta

Kazunaga Ishigaki

Kei Saito

Tomotaka Saito

Naminatsu Takahara

Tsuyoshi Hamada

Suguru Mizuno

Hirofumi Kogure

Minoru Tada

Hiroyuki Isayama

Kazuhiko Koike

\section{REFERENCES}

1. Iranmanesh P, Frossard JL, Mugnier-Konrad B, et al. Initial cholecystectomy vs sequential common duct endoscopic assessment and subsequent cholecystectomy for suspected gallstone migration: a randomized clinical trial. JAMA 2014;312:137-144.

2. Johnson AG, Hosking SW. Appraisal of the management of bile duct stones. Br J Surg 1987;74:555-560.

3. Ryozawa S, Itoi T, Katanuma A, et al. Japan Gastroenterological Endoscopy Society guidelines for endoscopic sphincterotomy. Dig Endosc 2018;30:149-173.

4. Yasuda I, Itoi T. Recent advances in endoscopic management of difficult bile duct stones. Dig Endosc 2013;25:376-385.

5. Doshi B, Yasuda I, Ryozawa S, Lee GH. Current endoscopic strategies for managing large bile duct stones. Dig Endosc 2018;30:5966.

6. Nakai Y, Kogure H, Yamada A, Isayama H, Koike K. Endoscopic management of bile duct stones in patients with surgically altered anatomy. Dig Endosc 2018;30:67-74.

7. Itoi T, Ryozawa S, Katanuma A, et al. Japan Gastroenterological Endoscopy Society guidelines for endoscopic papillary large balloon dilation. Dig Endosc 2018;30:293-309.

8. Ogura T, Imanishi M, Kurisu Y, et al. Prospective evaluation of digital single-operator cholangioscope for diagnostic and therapeutic procedures (with videos). Dig Endosc 2017;29:782-789.

9. Brewer Gutierrez OI, Bekkali NLH, Raijman I, et al. Efficacy and safety of digital single-operator cholangioscopy for difficult biliary stones. Clin Gastroenterol Hepatol 2018;16:918-926. 
10. Tsujino T, Yamada A, Isayama $\mathrm{H}$, et al. Experiences of biliary interventions using short double-balloon enteroscopy in patients with Roux-en-Y anastomosis or hepaticojejunostomy. Dig Endosc 2010;22:211-216.

11. Dhir V, Isayama H, Itoi T, et al. Endoscopic ultrasonographyguided biliary and pancreatic duct interventions. Dig Endosc 2017;29:472-485.

12. Minaga K, Kitano M. Recent advances in endoscopic ultrasoundguided biliary drainage. Dig Endosc 2018;30:38-47.

13. Komatsu Y, Kawabe T, Toda N, et al. Endoscopic papillary balloon dilation for the management of common bile duct stones: experience of 226 cases. Endoscopy 1998;30:12-17.

14. Tsujino T, Kawabe T, Komatsu Y, et al. Endoscopic papillary balloon dilation for bile duct stone: immediate and long-term outcomes in 1000 patients. Clin Gastroenterol Hepatol 2007;5:130137.

15. Fujita N, Maguchi H, Komatsu Y, et al. Endoscopic sphincterotomy and endoscopic papillary balloon dilatation for bile duct stones: a prospective randomized controlled multicenter trial. Gastrointest Endosc 2003;57:151-155.

16. Yasuda I, Fujita N, Maguchi H, et al. Long-term outcomes after endoscopic sphincterotomy versus endoscopic papillary balloon dilation for bile duct stones. Gastrointest Endosc 2010;72:11851191.

17. Ersoz G, Tekesin O, Ozutemiz AO, Gunsar F. Biliary sphincterotomy plus dilation with a large balloon for bile duct stones that are difficult to extract. Gastrointest Endosc 2003;57:156-159.

18. Madhoun MF, Wani S, Hong S, Tierney WM, Maple JT. Endoscopic papillary large balloon dilation reduces the need for mechanical lithotripsy in patients with large bile duct stones: a systematic review and meta-analysis. Diagn Ther Endosc 2014;2014:309618.

19. Park SJ, Kim JH, Hwang JC, et al. Factors predictive of adverse events following endoscopic papillary large balloon dilation: results from a multicenter series. Dig Dis Sci 2013;58:1100-1109.

20. Park JS, Jeong S, Lee DK, et al. Comparison of endoscopic papillary large balloon dilation with or without endoscopic sphincterotomy for the treatment of large bile duct stones. Endoscopy 2019;51:125-132.

21. Hakuta R, Kogure H, Nakai Y, et al. Endoscopic papillary large balloon dilation without sphincterotomy for users of antithrombotic agents: a multicenter retrospective study. Dig Endosc 2019;31:316-322.

22. Fujita Y, Iwasaki A, Sato T, et al. Feasibility of endoscopic papillary large balloon dilation in patients with difficult bile duct stones without dilatation of the lower part of the extrahepatic bile duct. Gut Liver 2017;11:149-155.

23. Schneider MU, Matek W, Bauer R, Domschke W. Mechanical lithotripsy of bile duct stones in 209 patients--effect of technical advances. Endoscopy 1988;20:248-253.

24. Chang WH, Chu CH, Wang TE, Chen MJ, Lin CC. Outcome of simple use of mechanical lithotripsy of difficult common bile duct stones. World J Gastroenterol 2005;11:593-596.
25. Garg PK, Tandon RK, Ahuja V, Makharia GK, Batra Y. Predictors of unsuccessful mechanical lithotripsy and endoscopic clearance of large bile duct stones. Gastrointest Endosc 2004;59:601-605.

26. Tandan M, Reddy DN. Extracorporeal shock wave lithotripsy for pancreatic and large common bile duct stones. World J Gastroenterol 2011;17:4365-4371.

27. Neuhaus H, Zillinger C, Born P, et al. Randomized study of intracorporeal laser lithotripsy versus extracorporeal shock-wave lithotripsy for difficult bile duct stones. Gastrointest Endosc 1998;47:327-334.

28. Veld JV, van Huijgevoort NCM, Boermeester MA, et al. A systematic review of advanced endoscopy-assisted lithotripsy for retained biliary tract stones: laser, electrohydraulic or extracorporeal shock wave. Endoscopy 2018;50:896-909.

29. Buxbaum J, Sahakian A, Ko C, et al. Randomized trial of cholangioscopy-guided laser lithotripsy versus conventional therapy for large bile duct stones (with videos). Gastrointest Endosc 2018;87:1050-1060.

30. Angsuwatcharakon P, Kulpatcharapong S, Ridtitid W, et al. Digital cholangioscopy-guided laser versus mechanical lithotripsy for large bile duct stone removal after failed papillary large-balloon dilation: a randomized study. Endoscopy 2019;51:1066-1073.

31. Deprez PH, Garces Duran R, Moreels T, et al. The economic impact of using single-operator cholangioscopy for the treatment of difficult bile duct stones and diagnosis of indeterminate bile duct strictures. Endoscopy 2018;50:109-118.

32. Moreels TG. Update in enteroscopy: new devices and new indications. Dig Endosc 2018;30:174-181.

33. Tanisaka Y, Ryozawa S, Mizuide M, et al. Usefulness of the "newly designed" short-type single-balloon enteroscope for ERCP in patients with Roux-en-Y gastrectomy: a pilot study. Endosc Int Open 2018;6:E1417-E1422.

34. Yamada A, Kogure H, Nakai Y, et al. Performance of a new shorttype double-balloon endoscope with advanced force transmission and adaptive bending for pancreaticobiliary intervention in patients with surgically altered anatomy: a propensity-matched analysis. Dig Endosc 2019;31:86-93.

35. Itoi T, Sofuni A, Itokawa F, et al. Diagnostic and therapeutic peroral direct cholangioscopy in patients with altered GI anatomy (with videos). Gastrointest Endosc 2012;75:441-449.

36. Koshitani T, Matsuda S, Takai K, et al. Direct cholangioscopy combined with double-balloon enteroscope-assisted endoscopic retrograde cholangiopancreatography. World J Gastroenterol 2012;18:3765-3769.

37. Hakuta R, Kogure H, Isayama H, et al. Electrohydraulic lithotripsy of large bile duct stones under direct cholangioscopy with a double-balloon endoscope. Endoscopy 2015;47:E519-E520.

38. Sato T, Kogure H, Nakai Y, Isayama H, Koike K. Electrohydraulic lithotripsy under double-balloon endoscope-assisted direct cholangioscopy for treatment of choledocholithiasis in a patient with Roux-en-Y gastrectomy. VideoGIE 2018;3:113-114.

39. Hakuta R, Kogure H, Nakai Y, et al. Successful endoscopic litho- 
tripsy using a new digital cholangioscope through an overtube placed by an enteroscope. Endoscopy 2018;50:E269-E271.

40. Tonozuka R, Itoi T, Sofuni A, et al. Novel peroral direct digital cholangioscopy-assisted lithotripsy using a monorail technique through the overtube in patients with surgically altered anatomy (with video). Dig Endosc 2019;31:203-208.

41. Mallery S, Matlock J, Freeman ML. EUS-guided rendezvous drainage of obstructed biliary and pancreatic ducts: report of 6 cases. Gastrointest Endosc 2004;59:100-107.

42. Tsuchiya T, Itoi T, Sofuni A, Tonozuka R, Mukai S. Endoscopic ultrasonography-guided rendezvous technique. Dig Endosc 2016;28:96-101.

43. Weilert F, Binmoeller KF, Marson F, Bhat Y, Shah JN. Endoscopic ultrasound-guided anterograde treatment of biliary stones following gastric bypass. Endoscopy 2011;43:1105-1108.

44. Iwashita T, Yasuda I, Doi S, et al. Endoscopic ultrasound-guided antegrade treatments for biliary disorders in patients with surgically altered anatomy. Dig Dis Sci 2013;58:2417-2422.

45. Itoi T, Sofuni A, Tsuchiya T, Ijima M, Iwashita T. Endoscopic ultrasonography-guided transhepatic antegrade stone removal in patients with surgically altered anatomy: case series and technical review (with videos). J Hepatobiliary Pancreat Sci 2014;21:E86-E93.

46. Iwashita T, Nakai Y, Hara K, Isayama H, Itoi T, Park DH. Endoscopic ultrasound-guided antegrade treatment of bile duct stone in patients with surgically altered anatomy: a multicenter retrospective cohort study. J Hepatobiliary Pancreat Sci 2016;23:227-233.

47. Nakai Y, Isayama H, Koike K. Two-step endoscopic ultrasonography-guided antegrade treatment of a difficult bile duct stone in a surgically altered anatomy patient. Dig Endosc 2018;30:125-127.

48. Hosmer A, Abdelfatah MM, Law R, Baron TH. Endoscopic ultrasound-guided hepaticogastrostomy and antegrade clearance of biliary lithiasis in patients with surgically-altered anatomy. Endosc Int Open 2018;6:E127-E130.

49. James TW, Fan YC, Baron TH. EUS-guided hepaticoenterostomy as a portal to allow definitive antegrade treatment of benign biliary diseases in patients with surgically altered anatomy. Gastrointest Endosc 2018;88:547-554.

50. Mukai S, Itoi T, Sofuni A, et al. EUS-guided antegrade intervention for benign biliary diseases in patients with surgically altered anatomy (with videos). Gastrointest Endosc 2019;89:399-407.

51. Kamiyama R, Ogura T, Okuda A, et al. Electrohydraulic lithotripsy for difficult bile duct stones under endoscopic retrograde cholangiopancreatography and peroral transluminal cholangioscopy guidance. Gut Liver 2018;12:457-462.

52. Nakai Y, Kogure H, Isayama H, Koike K. Endoscopic ultrasoundguided biliary drainage for benign biliary diseases. Clin Endosc 2019;52:212-219. 